\title{
Comentarios introductorios sobre la edición española de la obra de Andrew Samuels ¿Una nueva terapia para la política?
}

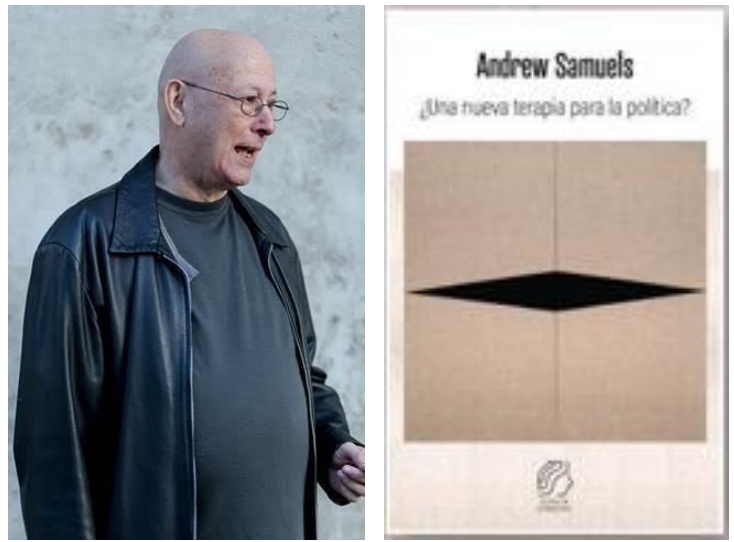

Londres: Karnac, 2015; ahora Lima: Gradiva, 2020

Realizada por Alejandro Ávila Espada ${ }^{1},{ }^{2}$

Es un honor presentar esta obra de Andrew Samuels, psicoterapeuta, profesor, activista y escritor de larga trayectoria; Profesor de Psicología Analítica - Centro de Estudios Psicoanalíticos, Universidad de Essex (Reino Unido) y también con una sólida trayectoria en la práctica privada como psicoanalista y consultor de orientación junguiana. Mi primer contacto con Andrew fue hace muchos años, con motivo de su participación en el Consejo de Psicoterapia del Reino Unido (más tarde, fue presidente del UKCP, 2009-2012), en reuniones que se celebraban en Bruselas y en otras ciudades europeas para encontrar criterios comunes para el desarrollo de la Psicoterapia en Europa. También fue fundador de Psicoterapeutas y Consejeros de Responsabilidad Social, y de nuestra institución compartida, la IARPP, y he coincidido con él en muchos gratos encuentros en el Consejo Directivo de IARPP. Entre sus numerosas actividades se incluye la actuación como profesor visitante: en el Colegio Goldsmith, de la Universidad de Londres / también en el Programa Postdoctoral en Psicoterapia and Psicoanálisis, de la Universidad de New York / City

${ }^{1}$ Ávila Espada, A. (2021). Comentarios introductorios sobre la edición española de la obra de Andrew Samuels: "¿Una nueva terapia para la política?". Clínica e Investigación Relacional, 15 (1): 294-297. [ISSN 1988-2939] [Recuperado de www.ceir.info] DOI: 10.21110/19882939.2021.150117

\footnotetext{
2 Este texto fue elaborado para la sesión de presentación por videoconferencia organizada por Gradiva, y en la que también intervinieron Andrew Samuels, Marie Saba, Lynn Alicia Franco, Eduardo Gatelumendi, Karla Escenaro el 3 de Octubre de 2020.
} 
University of Macau, y entre muchas otras, nuestro Instituto de Psicoterapia Relacional en Madrid, donde Andrew nos presentó un trabajo muy relevante sobre el tema que nos ocupa hoy y realizó un taller en nuestras Jornadas bienales en La Granja de San Ildefonso (Segovia, España) en 2018.

En la Conferencia que IARPP celebró en Roma (2016) Andrew nos mostró que un profesional políticamente consciente tiene muchas posibilidades de servir a la comunidad con una forma de vida políticamente comprometida como persona y profesional. Principalmente como un "espectador activo" participando en los argumentos de la vida personal y social, sin identificarse con ser un héroe sino ser un agente. Usando lo que él llama arte o puesta en escena "Agit-prop", y a través de un distanciamiento del drama humano personal -como en el Teatro de Brecht- podemos ver más en perspectiva lo que necesita ser cambiado en nuestra sociedad. Los psicoanalistas pueden ver -y mostrar- en perspectiva cómo pueden ser las cosas, no solo como son, revelando las contradicciones del conformismo social. Desde mi punto de vista, Andrew es un nuevo Bertold Brecht actual, no solo en el teatro sino en la sociedad.

La conferencia de Andrew en La Granja (2018) como apunté antes fue sobre el tema del libro que celebramos hoy. La charla fue una revisión de las posibilidades y límites para los analistas y terapeutas que quieren marcar la diferencia en la política, con focos en el liderazgo, la desigualdad económica y el cambio climático, y una sección sobre nuevos modelos de relaciones íntimas humanas (específicamente, promiscuidad y poliamor) que constituyen una metáfora de la resistencia contemporánea al orden político establecido.

El libro al que nos enfrentamos ahora establece que "El propósito principal de este libro es evaluar la contribución de la psicoterapia para evitar que pensemos como el estado quiere que pensemos. Hacer esto requiere una recalibración de la postura política general de la profesión ... había una cualidad de la mente radical ... presente en los inicios de la profesión de la psicoterapia, pero posteriormente se perdió en la búsqueda de la aceptación por parte de los poderosos ... recuperado, en parte mediante la adopción de una definición amplia de política ". pág. xiii

Esta redefinición de lo político desde el punto de vista del clínico profesional, implica una reconsideración de todos los niveles de su práctica: el tipo de clientes que acepta, los encuadres de trabajo que propone, su propia implicación y la de la persona en su cambio personal y su papel en lo social. ¿Nos importa algo más allá del bienestar subjetivo del paciente? Nuestra presencia está comprometida con el cambio, pero no es solo un cambio personal, sino colectivo. Y el cambio colectivo se substancia desde el compromiso de cambio efectivo en el nivel privado y público de cada persona. expresa. Este material es para uso científico y profesional exclusivamente y puede contener información clínica sensible. Los editores no se responsabilizan de los contenidos de los autores. Dirigir las consultas sobre derechos y autorizaciones a ceir@psicoterapiarelacional.es 
Como subrayó Neri Daurella (2018) en su comentario en La Granja al trabajo de Samuels, y acerca de la posibilidad de influir en el ámbito sociopolítico desde nuestra posición de psicoterapeutas, la obra de Andrew nos ilustra sobre su tensión entre el entusiasmo y el escepticismo con un conmovedor poema de un superviviente del holocausto, "No conseguí salvar una sola vida". Es una impotencia que nos duele a todos, contra la que nos rebelamos como subraya Orange (2016) pues nada humano nos es ajeno, y la motivación de salvar a los demás, el duelo por lo que no podemos conseguir ni a nivel individual ni colectivo, y lo limitado de nuestras posibilidades de intervención nos cuestionan constantemente. Pero compartir estos sentimientos y estos pensamientos con colegas como Andrew Samuels o Donna Orange nos hace sentir muy bien acompañados en el empeño.

El cambio es una intersección de lo personal y lo colectivo. El cambio personal no es siempre posible o duradero sin un cambio social, y viceversa. Pero el cambio social necesita presencia, participación, con la mirada puesta en la transformación social que le permita al individuo una experiencia de estar con otros en desarrollo. Una Presencia como decía Levinas: "La presencia de personas en toda la fuerza de su identidad insustituible, en la fuerza de su inevitable responsabilidad". Esta presencia / participación asume el sacrificio de dejar la acogedora calidez de nuestros mundos privados para vernos a nosotros mismos como parte de toda una sociedad. Pero no un compromiso heroico, un compromiso para promulgar en cualquier momento que tengamos la oportunidad de estar presentes en el colectivo.

Nuestra elección es tomar conciencia en la intersección de la subjetividad y la compleja sociedad en la que vivimos. Esa es nuestra historia como seres humanos, viviendo inevitablemente en contextos donde las explicaciones y la significación solo pueden alcanzarse a través de un conocimiento profundo de nuestra posición en el contexto, donde cualquier acción u omisión es significativa. Eso es lo que el psicoanalista social argentino Pichon Rivière llamó "Sujeto situado" (Sujeto comprometido con el conocimiento de su agencia en contexto). También tenemos que revisar nuestra posición como analistas-sujetos sociales.

Nuestro silencio ya no es suficiente como clínicos, el "giro ético" (Donna Orange, 2011, 2016 , 2017) nos espera como los relacionales que pretendemos ser. La memoria y la historia forman parte de nuestra esencia, y tenemos la posibilidad de integrarnos ambos a lo largo de nuestro desarrollo personal, pero principalmente como clínicos llamados a actuar de forma creativa y transformadora. 


\section{Referencias}

Daurella, N. (2018). Discusión de la ponencia ¿Una nueva terapia para la política? de Andrew Samuels. Clínica e Investigación Relacional, 12 (1): 49-59.

Orange, D.M. (2011). The Suffering Stranger: Hermeneutics for Everyday Clinical Practice. Nueva York: Routledge

Orange, D.M. (2016). Nourishing the Inner Life of Clinicians and Humanitarians; The ethical turn in Psychoanalysis New York: Routledge.

Orange, D.M. (2017). Climate Crisis, Psychoanalysis and Radical Ethics. New York: Routledge.

Samuels, A. (1993). The Political Psyche. London and New York: Routledge

Samuels, A. (2001). Politics on the Couch: Citizenship and the Internal Life. London and New York: Karnac Books/Other Press.

Samuels, A. (2014). Persons, Passions, Psychotherapy, Politics London and New York: Routledge.

Samuels, A. (2015). A New Therapy for Politics? London: Karnac.

Samuels, A. (2018). ¿Una nueva terapia para la política?. Clínica e Investigación Relacional, 12 (1): 3448. 